\section{OPEN JOURNAL SYSTEMS}

ISSN:2237-2202
Available on line at Directory of Open Access Journals

Journal of Hyperspectral Remote Sensing v.9, n.3 (2019) 116-130

www.periodicos.ufpe.br/revistas/jhrs

\section{Journal of Hyperspectral Remote Sensing www.ufpe.br/jhrs}

\title{
Analysis of the natural vulnerability of soil loss in the Uruburetama Massif/CE
}

\author{
Eduardo V. Freires ${ }^{*}$, Cláudio Â. da Silva Neto", Maykon T. da Silva ${ }^{*}$, Cynthia R. Duarte ${ }^{* *}$, \\ César Ulisses V. Veríssimo**, Daniel D. M. Gomes ${ }^{* * *}$ \\ "Programa de Pós-Graduação em Geologia, Universidade Federal do Ceará (UFC), Fortaleza/CE. \\ E-mail: eduardovgeo@gmail.com (autor correspondente); claudioasn@gmail.com; maykontargino@hotmail.com. \\ ${ }^{* *}$ Departamento de Geologia, Universidade Federal do Ceará (UFC), Fortaleza/CE. \\ E-mail: cynthia.duarte@ufc.br; cesarulisses85@gmail.com \\ ${ }^{* * *}$ Departamento de Geografia, Universidade de Pernambuco (UPE), Campus Garanhuns. \\ E-mail: daniel.gomes@upe.br
}

Received 6 July 2019, accepted 3 December 2019

\begin{abstract}
Knowledge of the physical characteristics of a given environment is essential to ensure the effective management of natural resources. In this sense, the survey of morphometric variables is fundamental to guide land use planning. This work evaluated the natural vulnerability to soil degradation of the Uruburetama Massif humid hillside, using as evaluation support the morphometric variables extracted from the ALOS PALSAR Digital Elevation Model (DEM). For this, the slope, slope orientation, horizontal and vertical curvature variables were integrated in GIS environment, from a multicriteria analysis, where weights were established in percentages for each variable and grades from 0 to 10 for their respective thematic classes. From the natural vulnerability to soil loss map generated, it was found that practically all slopes of the humid hillside of the massif have medium to very high vulnerability. The slopes of the east, north and, especially, northeastern oriented massif showed the highest occurrence of high and very high vulnerability. The very low and low vulnerability classes are mainly distributed in the area surrounding the wetland, which corresponds to the backwoods depression, and in sectors of some valleys, where the process of pedogenesis is superior to morphogenesis. The map of natural vulnerability to soil degradation is an important instrument for environmental planning, serving as a support for orientation and supervision of use and occupation, in order to reduce damage and ensure sustainable agricultural development.
\end{abstract}

Keywords: DEM, ALOS PALSAR, geomorphometric variables, GIS.

\section{Análise da vulnerabilidade natural à perda de solos da vertente úmida do Maciço de Uruburetama/CE}

\section{Resumo}

O conhecimento das características físicas de determinado ambiente é imprescindível para garantir a gestão dos recursos naturais de forma eficaz. Nesse sentido, o levantamento das variáveis morfométricas é fundamental para orientar o ordenamento do uso ocupação do solo. Diante do exposto, esse trabalho avaliou a vulnerabilidade natural à degradação dos solos da vertente úmida do Maciço de Uruburetama/CE, tendo como suporte de avaliação as variáveis morfométricas extraídas do Modelo Digital de Elevação (MDE) ALOS PALSAR. Para isso as variáveis declividade, orientação das vertentes, curvatura horizontal e vertical foram integradas em ambiente SIG, a partir de uma análise multicritério, onde foram estabelecidos pesos em percentuais para cada variável e notas de 0 a 10 para suas respectivas classes temáticas. A partir do mapa de vulnerabilidade natural à perda de solos gerado, constatou-se que praticamente todas as encostas da vertente úmida do maciço apresentam vulnerabilidade média a muito alta. As vertentes do maciço com orientação leste, norte e, sobretudo, nordeste apresentaram maior ocorrência de vulnerabilidade alta e muito alta. As classes de vulnerabilidade muito baixa e baixa se distribuem principalmente na área de entorno da vertente úmida, que corresponde a depressão sertaneja, e em setores de alguns vales, onde o processo de pedogênese é superior a morfogênese. O mapa de vulnerabilidade natural à degradação dos solos é um importante instrumento para o planejamento ambiental, servindo como suporte para orientação e físcalização de uso e ocupação, no intuito de reduzir os danos e garantir o desenvolvimento agrícola sustentável.

Palavras-chave: MDE, ALOS PALSAR, variáveis geomorfométricas, SIG. 


\section{Introdução}

A erosão dos solos é um fenômeno natural que modela a superfície da Terra. Esse fenômeno atua com maior intensidade em paisagens que possuam algum tipo de declividade, geralmente superior a $3^{\circ}$. A erosão do solo pode ser dividida em natural e antrópica. A erosão natural é um fenômeno que compõe o processo de formação dos solos ao longo do tempo, enquanto que a erosão antrópica, também conhecida por erosão acelerada, é responsável por sua degradação.

Os problemas resultantes da erosão antrópica dos solos são: remoção de nutrientes; redução da penetração das raízes e do armazenamento de água; perda de áreas úteis para fins agropecuários; aumento do assoreamento dos corpos d'água e a consequente poluição dos recursos hídricos pelo transporte de defensivos agrícolas (Jorge e Guerra, 2013).

As variações nas taxas de erosão são determinadas pela interação dos seguintes fatores controladores: erosividade da chuva; erodibilidade do solo; cobertura vegetal; e características das encostas. Ainda, as intervenções humanas podem alterar esses fatores por meio de adoção de práticas agrícolas adequada, ou ausência delas, contribuindo para acelerar ou retardar os processos erosivos (Guerra, 2005).

Os fatores relacionados às características das encostas podem afetar a estabilidade dos solos de diferentes maneiras, seja pela declividade ou pelo comprimento e forma da encosta (Guerra, 2005). As características geométricas do relevo, tais como: convexas, côncavas e retilíneas, que resultam da ação de processos erosivos e/ou deposicionais no tempo, igualmente condicionam a espacialização de processos subsequentes. Entre o topo e o fundo do vale transitam sedimentos e diversos elementos dentríticos ou solúveis, por meio de mecanismos associados a água, ao vento ou ao gelo, em interação com as forças da gravidade (Coelho Netto, 2005).

A vertente, que representa a conexão dinâmica entre o interflúvio e o fundo do vale, poderá ter suas formas originais e antropogênicas reconhecidas para determinação de limiares no jogo de forças entre resistência e destruição (Dylik, 1968).

De acordo com Loureiro e Ferreira (2013), o conhecimento da dinâmica dos processos erosivos e dos fatores condicionantes dos movimentos de massa é de extrema relevância para um planejamento e gestão ambiental eficazes, já que a compreensão da gênese e a abrangência desses fenômenos se fazem essenciais para mitigar as perdas materiais e humanas que eles geram.

Nesse sentido, conhecer as variáveis físicas que controlam a dinâmica sedimentar de determinado ambiente é imprescindível para orientar as atividades agrícolas e a ocupação do solo, com vista a garantir a sustentabilidade e a reduzir os riscos associados às intervenções humanas.

Diante do fato exposto, esta pesquisa avaliou a vulnerabilidade natural a perda de solos da vertente úmida do Maciço de Uruburetama, no estado do Ceará, tendo como suporte para avaliação as variáveis morfométricas (declividade, curvatura vertical, curvatura horizontal e orientação das vertentes) derivadas do Modelo Digital de Elevação (MDE) gerado a partir de imagens orbitais do sensor ALOS PALSAR.

\section{Material e métodos}

\section{Caracterização da área de estudo}

A serra de Uruburetama está localizada na porção setentrional do estado do Ceará, distante 100 $\mathrm{km}$ da capital, Fortaleza. Trata-se de um maciço residual montanhoso em formato circular com um pequeno alongamento na direção $\mathrm{E}-\mathrm{W}$ (Brandão e Freitas, 2014). Esse maciço é extremamente dissecado em colinas e cristas, possui vales superimpostos, em formato de $\mathrm{V}$, dispostos de forma paralela com orientação NW-SE (Brandão, 2003). A porção úmida/subúmida da serra corresponde às encostas norte-oriental e à superfície de cimeira (platô da serra). O maciço é fortemente tectonizado e intensamente fraturado, em que em muitos casos, a rede de drenagem se adapta a essas estruturas (Souza e Oliveira, 2006).

A área de estudo compreende a vertente úmida da serra de Uruburetama e adjacências, totalizando $1.342,73 \mathrm{~km}^{2}$. Como pode ser observado na Tabela 1 e na Figura 1, ela está inserida, em diferentes proporções, dentro do limite administrativo de nove municípios do estado do Ceará, que são: Irauçuba, Itapajé, Itapipoca, Pentecoste, Tejuçuoca, Trairi, Tururu, Umirim e Uruburetama. 
Tabela 1 - Proporção de abrangência dos municípios na área de estudo.

\begin{tabular}{ccc}
\hline Municípios & $\begin{array}{c}\text { Área abrangida em } \\
\mathbf{K m}^{\mathbf{2}}\end{array}$ & Percentual de área \\
\hline Irauçuba & 21,42 & $1,60 \%$ \\
Itapajé & 379,85 & $28,29 \%$ \\
Itapipoca & 503,22 & $37,48 \%$ \\
Pentecoste & 21,55 & $1,61 \%$ \\
Tejuçuoca & 61,30 & $4,57 \%$ \\
Trairi & 2,02 & $0,15 \%$ \\
Tururu & 119,71 & $8,92 \%$ \\
Umirim & 136,66 & $10,18 \%$ \\
Uruburetama & 97,00 & $7,22 \%$ \\
Total & 1342,73 & $100 \%$ \\
\hline
\end{tabular}

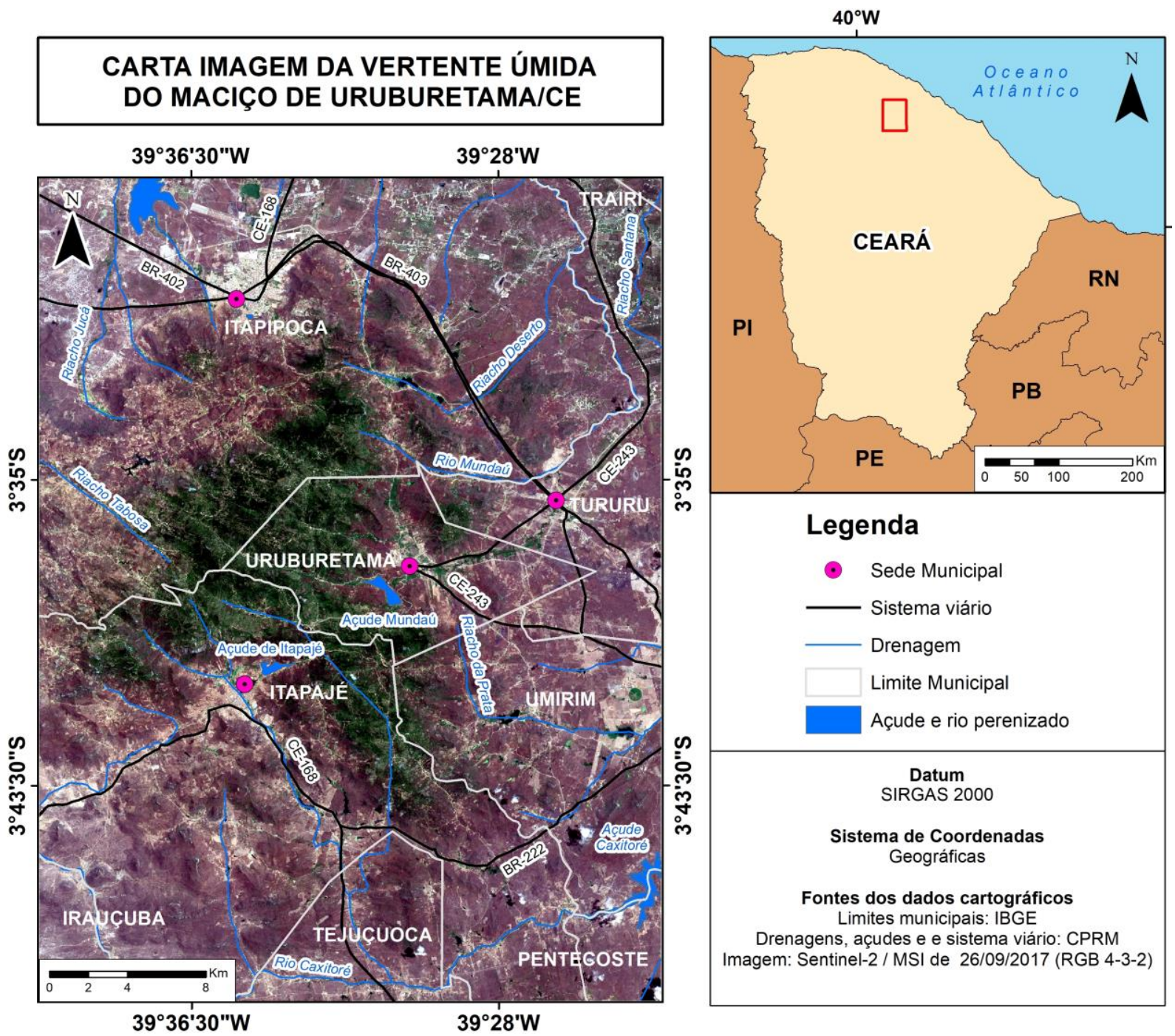

Figura 1 - Localização da vertente úmida da serra de Uruburetama, na região norte do estado do Ceará.

\section{Materiais}

Para análise da vulnerabilidade natural à perda de solos no maciço de Uruburetama foi utilizada como suporte de avaliação uma cena do sensor ALOS PALSAR, orbita absoluta 27262, frame 7110 , com resolução espacial de $12,5 \mathrm{~m}$, disponibilizado na base de dados do Alaska Satellite
Facility, da Agência de Exploração Aeroespacial do Japão (JAXA). A cena foi imageada pelo sensor em 8 de março de 2011 (Figura 2). Dentre os Modelos Digitais de Elevação gratuitos a imagem ALOS PALSAR se destaca em virtude de sua maior resolução espacial. As imagens ASTER-GDEM e SRTM por exemplo, com grande 
empregabilidade em estudos ambientais, possuem resolução espacial de $30 \mathrm{~m}$. Além disso, conforme Becek (2014), as avaliações de precisão indicam que o MDE ALOS é mais preciso que os demais modelos gratuitos de abrangência global disponível. Duarte et al. (2019), ao comparar a precisão vertical entre os três modelos mencionados, constataram que a imagem ALOS foi a que apresentou melhor resultado na delimitação de uma bacia hidrográfica na
Amazônia.

O software ArcGIS ${ }^{\circledR}$ 10.3.1 foi empregado no processamento da imagem; e, subsidiariamente, os arquivos vetoriais dos limites municipais e das unidades federativas, bem como os de hidrografia, rodovias e sedes municipais foram obtidos nos sítios eletrônicos, respectivamente, do Instituto Brasileiro de Geografia e Estatística (IBGE) e da Companhia de Pesquisa de Recursos Minerais (CPRM).

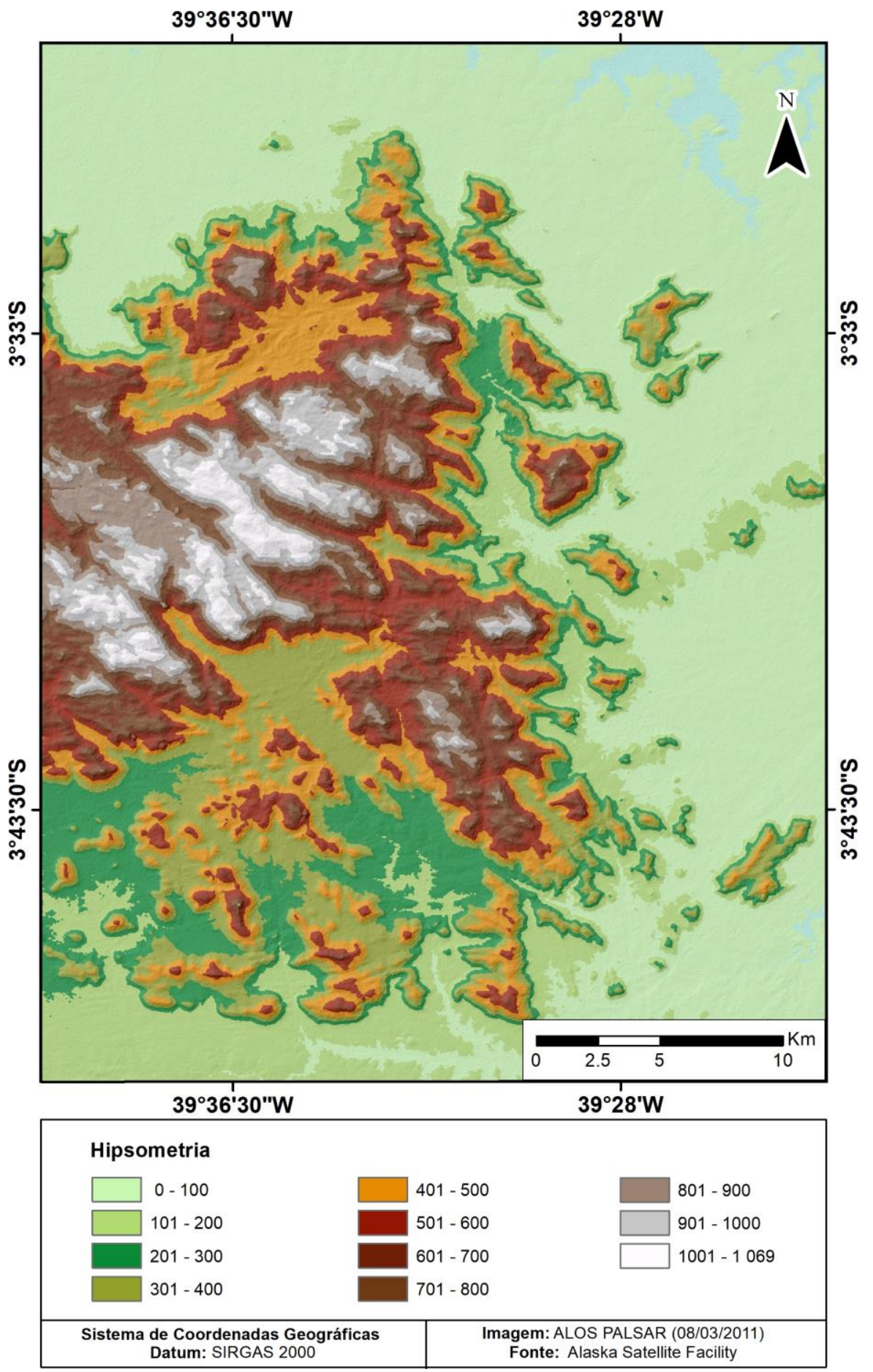

Figura 2 - Hipsometria da vertente úmida da serra de Uruburetama, na região norte do estado do Ceará elaborado a partir do MDE ALOS PALSAR. 


\section{Métodos}

A pesquisa foi desenvolvida em três etapas (Figura 3). A primeira etapa consistiu na obtenção da cena do sensor ALOS PALSAR e na revisão bibliográfica. A obtenção das variáveis morfométricas deu-se conforme metodologia descrita por Valeriano (2008) a partir do modelo digital de elevação. Para análise multicritério foi utilizado como referência Crepani et al. (1996), que atribuíram valores de estabilidade $\left(\begin{array}{lll}1 & \text { a } & 3\end{array}\right)$ às categorias morfodinâmicas estabelecidas na ecodinâmica de Tricart (1977): meios estáveis, meios intergrades e meios instáveis, como pode observado na Tabela 2.

Crepani et al. (1996) estabeleceram 21 classes de vulnerabilidade a perda de solos dentro do intervalo de 1 a 3. Estas classes estão distribuídas em situações onde há o predomínio dos processos de pedogênese (às quais se atribuem valores próximos de 1,0), passando por quadros intermediários (às quais se atribuem valores próximos de 2,0), até situações de predomínio dos processos de morfogênese (às quais se atribuem valores próximos de 3,0). Nesse sentido, os valores propostos diminuem conforme a maior estabilidade dos solos e aumentam em decorrência de sua maior instabilidade.

Na segunda etapa houve o processamento do MDE ALOS PALSAR visando a extração de variáveis morfométricas (declividade, curvatura vertical, curvatura horizontal e orientação das vertentes) a partir da ferramenta Spatial Analyst do software $\operatorname{ArcGIS}^{\circledR}$ 10.3.1. Em seguida, foram definidas as classes temáticas das variáveis, e posteriormente, com o objetivo de transformar os intervalos dessas classes para valores inteiros, foi realizada uma reclassificação.

A terceira e última etapa correspondeu à álgebra de mapas realizada a partir da análise multicritério com a ferramenta Weighted Overlay. Nesta etapa, como pode ser observado na Tabela 3, para cada variável analisada foram estabelecidos pesos em percentuais conforme o grau de importância para o fenômeno analisado (erosão e movimento de massa), totalizando $100 \%$. Adaptando a metodologia de Crepani et al. (1996), foram definidas notas de 1 a 10 para as classes de cada variável mapeada, conforme a relevância assumida no evento deflagrado. Para esta pesquisa foram adotados valores inteiros de $1 \mathrm{a} 10$ em conformidade com as pesquisas de Brandão (2003) e Carmo et al. (2015).

Tabela 2 - Avaliação da estabilidade das categorias morfodinâmicas.

\begin{tabular}{|c|c|c|}
\hline $\begin{array}{c}\text { Categoria } \\
\text { morfodinâmica }\end{array}$ & $\begin{array}{l}\text { Relação morfogênese } \\
\text { pedogênese }\end{array}$ & Valor \\
\hline Estável & $\begin{array}{l}\text { Prevalece a } \\
\text { pedogênese }\end{array}$ & 1 \\
\hline Intermediária & $\begin{array}{c}\text { Equilíbrio } \\
\text { pedogênese/morfogênese }\end{array}$ & 2 \\
\hline Instável & $\begin{array}{l}\text { Prevalece a } \\
\text { morfogênese }\end{array}$ & 3 \\
\hline
\end{tabular}

Fonte: Crepani et al. (1996).

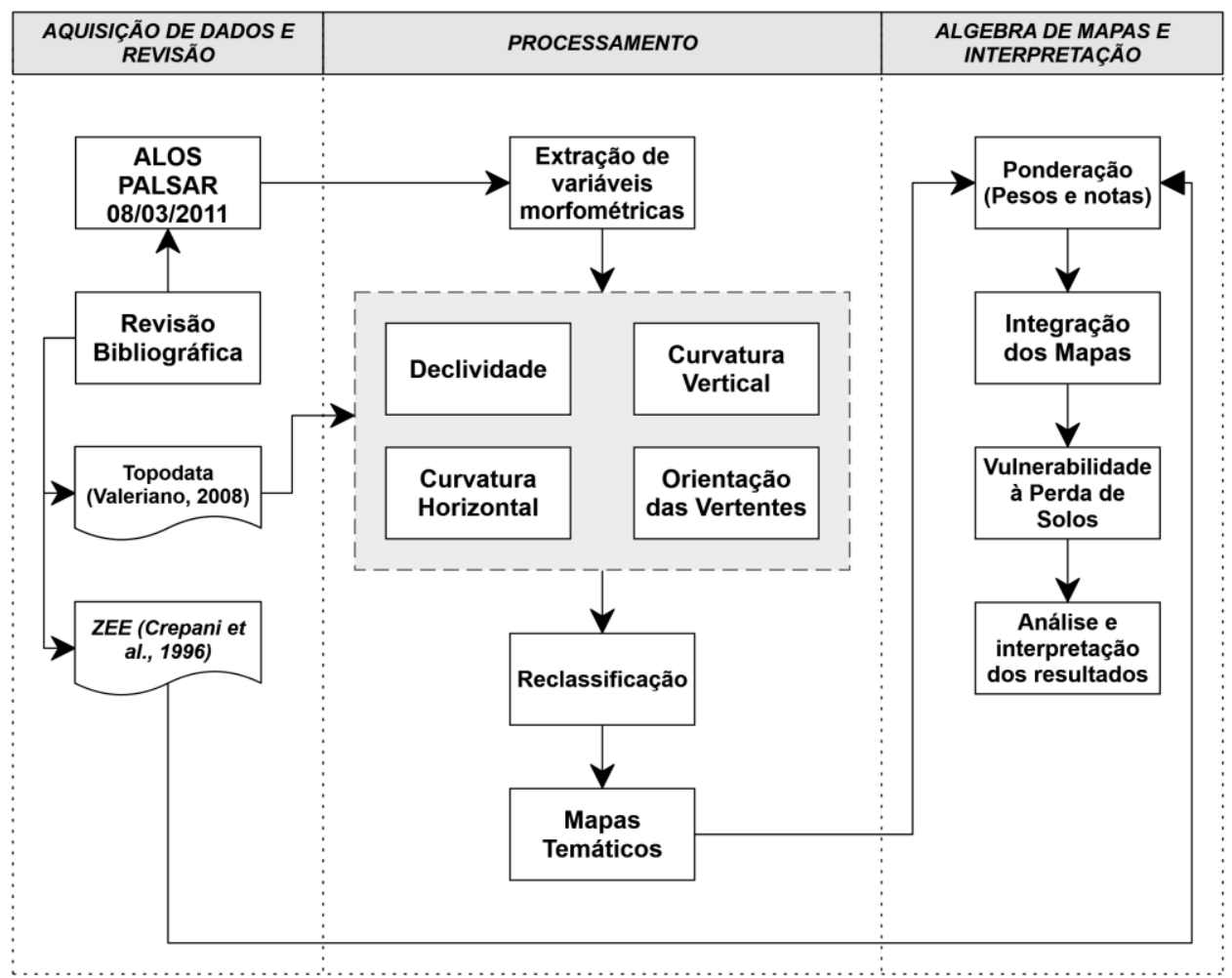

Figura 3 - Fluxograma com as principais etapas seguidas para o desenvolvimento da pesquisa. 
Tabela 3 - Pesos e notas atribuídos às e classes temáticas.

\begin{tabular}{|c|c|}
\hline \multicolumn{2}{|c|}{ Declividade } \\
\hline Peso (35\%) & Notas \\
\hline $0-3 \%$ & 1 \\
\hline $3-8 \%$ & 2 \\
\hline $8-20 \%$ & 4 \\
\hline $20-45 \%$ & 6 \\
\hline $45-75 \%$ & 8 \\
\hline$>75 \%$ & 10 \\
\hline \multicolumn{2}{|c|}{ Curvatura Vertical } \\
\hline Peso (30\%) & Notas \\
\hline Muito Convexa & 2 \\
\hline Convexa & 4 \\
\hline Retilínea & 6 \\
\hline Côncava & 8 \\
\hline Muito Côncava & 10 \\
\hline \multicolumn{2}{|c|}{$\begin{array}{l}\text { Curvatura Horizontal } \\
\end{array}$} \\
\hline Peso $(20 \%)$ & Notas \\
\hline Muito Divergente & 2 \\
\hline Divergente & 4 \\
\hline Planar & 6 \\
\hline Convergente & 8 \\
\hline Muito Convergente & 10 \\
\hline \multicolumn{2}{|c|}{ Orientação Das Vertentes } \\
\hline Peso (15\%) & Notas \\
\hline Noroeste & 1 \\
\hline Oeste & 2 \\
\hline Sudeste & 4 \\
\hline Sul & 5 \\
\hline Sudoeste & 6 \\
\hline Norte & 8 \\
\hline Leste & 9 \\
\hline Nordeste & 10 \\
\hline
\end{tabular}

Os mapas temáticos das variáveis morfométricas, com seus respectivos pesos e notas, foram submetidos a álgebra de mapas a partir da Equação 1 .

$$
\begin{gathered}
V=d * 0,35+c v * 0,30+c h * 0,20+o v \\
* 0,15(1)
\end{gathered}
$$

Em que: $V$ corresponde à vulnerabilidade natural à degradação dos solos; $d$ à declividade; $c v$ à curvatura vertical; $c h$ à curvatura horizontal; e $o v$ à orientação de vertente.

Com a ponderação dos pesos e notas, obtevese o mapa de vulnerabilidade natural a perda de solos, em seguida, foi realizada a análise e interpretação dos resultados.

\section{Resultados e discussão}

Os fatores relativos às encostas tais como a - declividade, o comprimento e a forma, podem afetar a erodibilidade dos solos de diferentes maneiras. Com a ação e interação desses fatores ocorrem os mecanismos de infiltração de água no solo, armazenamento e escoamento em superfície e subsuperfície. Consequentemente a ação da água, como agente erosivo, deve ser compreendida, levando-se em conta a complexidade desses fatores (Guerra, 2005).

\section{Declividade}

A declividade é a inclinação maior ou menor do relevo em relação ao horizonte. Seus valores podem ser expressos em graus, de $0^{\circ}$ a $90^{\circ}$, porém é mais comumente expressa em porcentagem, de zero a infinito (Valeriano, 2008; Torres et al., 2012). Tem influência direta sobre o equilíbrio entre a infiltração de água no solo e escoamento superficial, além de controlar a intensidade dos fluxos de matéria, que vai variar conforme o grau de inclinação da vertente (Valeriano, 2008).

O estudo da declividade é primordial para análise geomorfológica. Ao associá-la à pedologia, à cobertura vegetal e a fatores como o clima e orientação das vertentes, é possível deduzir os riscos de desmoronamentos ou deslizamentos de terras, auxiliando assim no planejamento e na prevenção de desastres naturais (Valeriano, 2008).

Ainda relacionado à declividade, o escoamento e a infiltração apresentam forte interação com ela, que associada à litologia, tipo de solos, cobertura vegetal, precipitação e outros fatores morfométricos podem indicar um grau maior ou menor da probabilidade do risco de erosão das vertentes (Pradhan, 2010).

Conforme a declividade do terreno (Figura 4), o desenvolvimento dos solos (pedogênese) pode ocorrer por meio de fluxo com componente vertical ou perpendicular, ou o desenvolvimento dos processos erosivos (morfogênese) em função de fluxos com componentes paralelos que se caracterizam pela remoção de detritos das vertentes, resultando na perda de solos e esculturação do relevo (Silva Neto, 2013).

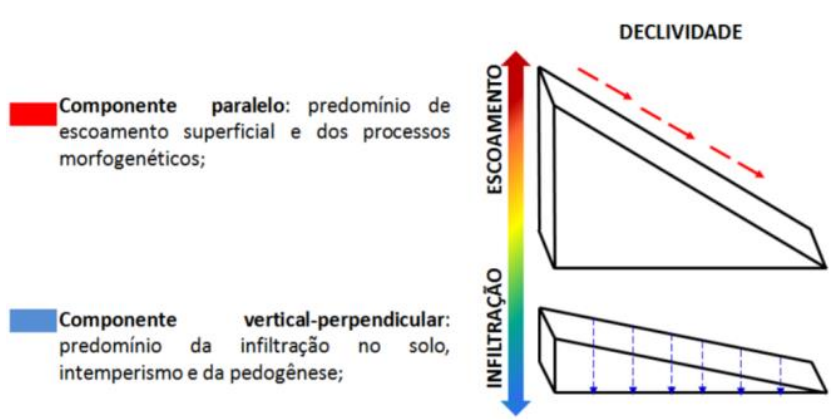

Figura 4 - Declividade de vertente e processos morfogenéticos e pedogenético. Fonte: Silva Neto (2013). 
A Figura 5 apresenta o mapa de declividade gerado a partir do MDE ALOS PALSAR. As classes de declividade foram definidas conforme Empresa Brasileira de Pesquisa Agropecuária (EMBRAPA, 1979), como podem ser observadas na Tabela 4.

$\mathrm{Na}$ tabela 5 podem ser observadas as classes de declividade $\mathrm{e}$ as suas respectivas áreas de abrangência em percentuais.
Vale destacar que a declividade do terreno é um parâmetro relevante para o disciplinamento do uso da terra, pois serve de patamar para importantes elementos restritivos, a exemplo das áreas de preservação permanente, que devem ser mantidas em declives superiores a $45^{\circ}$ (Torres et al., 2012).

Em virtude da relevância dessa variável para deflagração dos processos de transporte sedimentar, foi atribuído peso de $35 \%$ na análise multicritério.
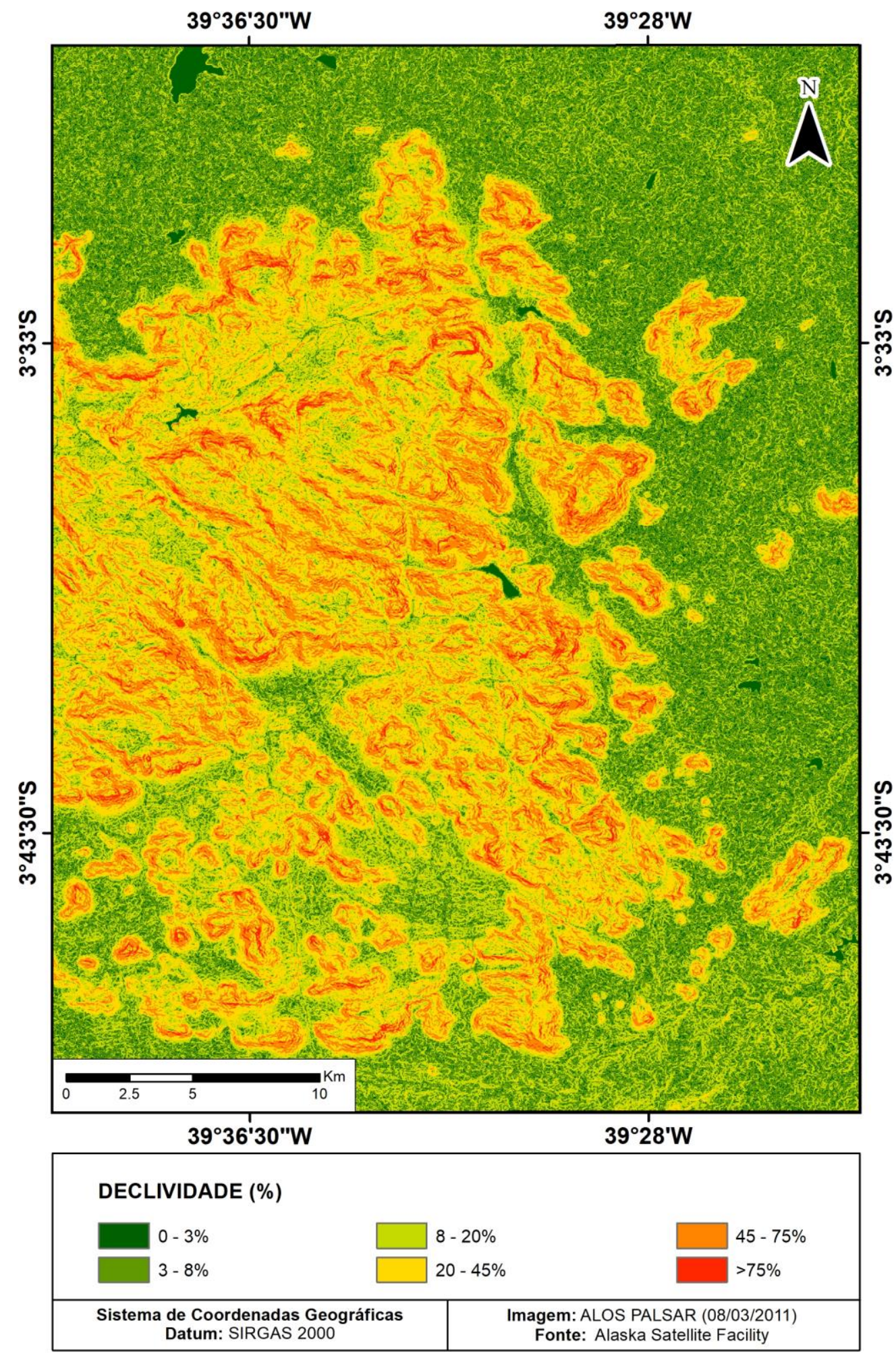

Figura 5 - Mapa de declividade em percentuais na vertente úmida da serra de Uruburetama. 
Tabela 4 - Classes de declividade

\begin{tabular}{lc}
\hline Classes de Relevo & Declividade (\%) \\
\hline Plano & $0-3 \%$ \\
Suave ondulado & $3-8 \%$ \\
Ondulado & $8-20 \%$ \\
Forte Ondulado & $20-45 \%$ \\
Montanhoso & $45-75 \%$ \\
Escarpado & $>75 \%$ \\
\hline
\end{tabular}

Fonte: EMBRAPA (1979).

Tabela 5 - Classes de Declividade e área de abrangência em percentuais

\begin{tabular}{lr}
\hline Classes de Relevo & Área (\%) \\
\hline Plano & 13,36 \\
Suave ondulado & 47,41 \\
Ondulado & 24,87 \\
Forte Ondulado & 9,22 \\
Montanhoso & 4,48 \\
Escarpado & 0,65 \\
\hline
\end{tabular}

Curvatura vertical e curvatura horizontal

A curvatura vertical expressa o formato da vertente quando observada em perfil, ou seja, referese ao caráter convexo/côncavo do terreno, como pode ser visto na Figura 6 (Valeriano, 2008; Bispo et al., 2011).

A análise dos tipos de curvaturas verticais de vertentes é importante do ponto de vista morfológico, pedogenético e hidrológico. Ao associar a curvatura vertical à declividade, ao clima e ao substrato do terreno, pode-se inferir o tipo de solo formado na vertente, sua possível movimentação por gravidade e até prováveis pontos de acumulação. Sua aplicabilidade também é bem-sucedida no mapeamento geomorfológico e pedológico (Carmo et al., 2015)

A curvatura horizontal refere-se ao formato da vertente quando observada em projeção horizontal (Valeriano, 2008). A curvatura horizontal corresponde ao caráter divergente ou convergente das linhas de fluxo no terreno (Figura 6). A curvatura divergente refere-se ao alargamento das linhas de fluxos, podendo indicar topografia mais suave ou vales abertos, enquanto que o caráter convergente sugere um estreitamento dos caminhos do escoamento formando vales mais fechados.

Quando associada a outras variáveis como curvatura vertical e declividade, a curvatura horizontal exerce um importante controle sobre a vazante dos fluxos superficiais (Hilberts et al., 2004).

As curvaturas vertical e horizontal apresentam influência direta nos processos de migração e acúmulo de água, minerais e materiais orgânicos no solo através da superfície, proporcionados pela gravidade (Bispo et al., 2011).

As classes de curvatura vertical (côncavo, retilíneo ou convexo) e horizontal (convergente, planar ou divergente) ao serem combinadas originam diferentes formas do terreno, como pode visualizado na Figura 6.

Conforme descrito por Valeriano (2008), os casos extremos de combinações de curvatura do terreno são representados pela forma côncavoconvergente, que apresenta a máxima concentração e acúmulo do escoamento, e pela forma convexadivergente, com máxima dispersão do escoamento. As combinações intermediárias têm características hidrológicas mais dependentes das relações entre as intensidades (módulos) dos efeitos individuais.

Como pode ser observado na Figura 7, foram definidas cinco classes para curvatura vertical: muito côncava, côncava, retilínea, convexa e muito convexa. Para curvatura horizontal (Figura 8), também foram definidas cinco classes: muito convergente, convergente, planar, divergente, muito divergente. Nas tabelas 6 e 7 podem ser visualizados as classes de curvatura horizontal e vertical com suas respectivas áreas de abrangência em percentuais.

Tabela 6 - Classes de Curvatura Horizontal e área de abrangência em percentuais.

\begin{tabular}{lr}
\hline Classes de & Área (\%) \\
Curvatura Horizontal & 2,01 \\
\hline Muito Convergente & 15.76 \\
Convergente & 58,71 \\
Planar & 20,31 \\
Divergente & 3,21 \\
Muito Divergente & \\
\hline
\end{tabular}

Tabela 7 - Classes de Curvatura Vertical e área de abrangência em percentuais.

\begin{tabular}{lr}
\hline Classes de & Área (\%) \\
Curvatura Vertical & 2,85 \\
\hline Muito Côncava & 27,22 \\
Côncava & 46,30 \\
Retilínea & 22,32 \\
Convexa & 1,31 \\
\hline Muito Convexa & \\
\hline
\end{tabular}


Para essas variáveis os pesos em percentuais atribuídos foram de $20 \%$ para curvatura horizontal e
$30 \%$ para curvatura vertical, por esta variável ter maior relevância

na análise.

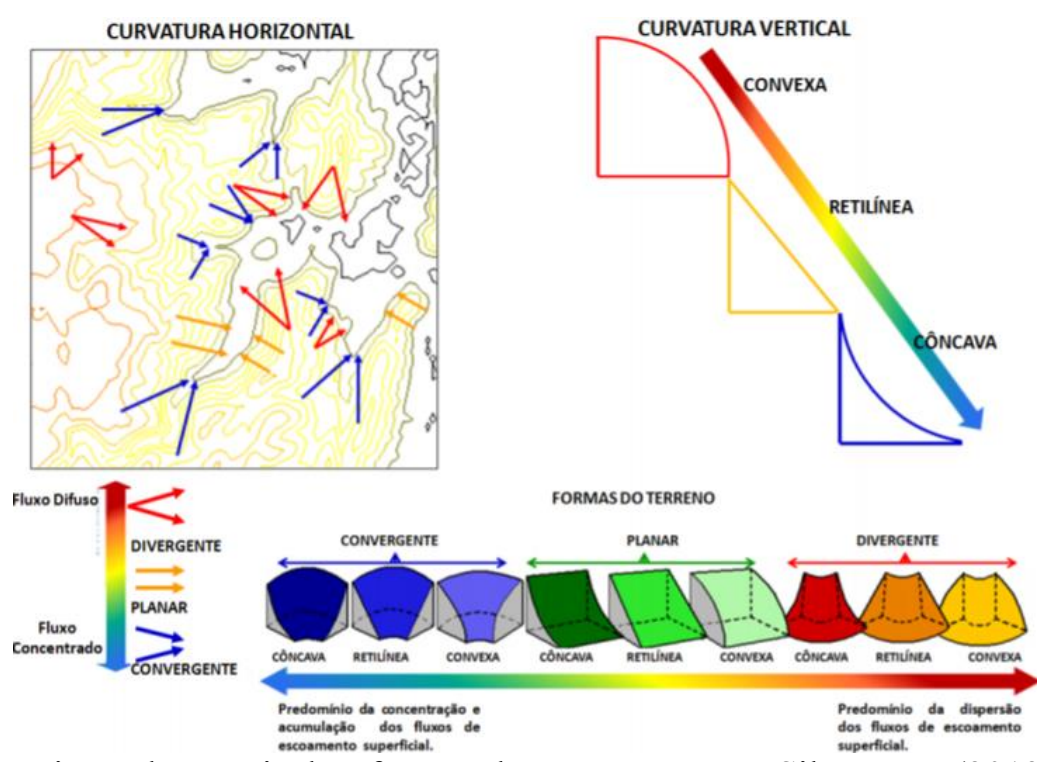

Figura 6 - Curvaturas Horizontal e Vertical, e formas do terreno. Fonte: Silva Neto (2013) adaptado de Valeriano (2008).

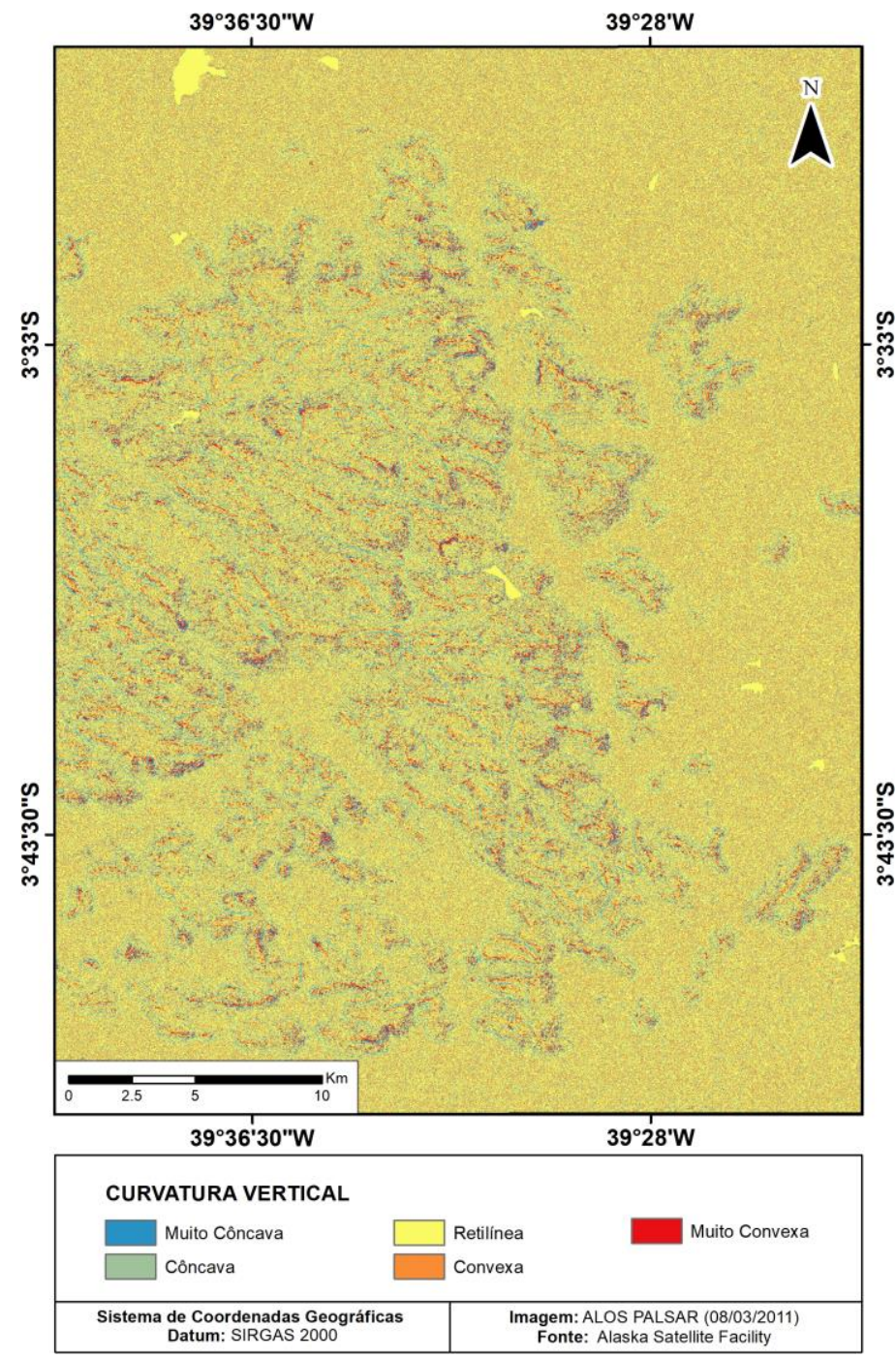

Figura 7 - Mapa de curvatura vertical da vertente úmida da serra de Uruburetama. 


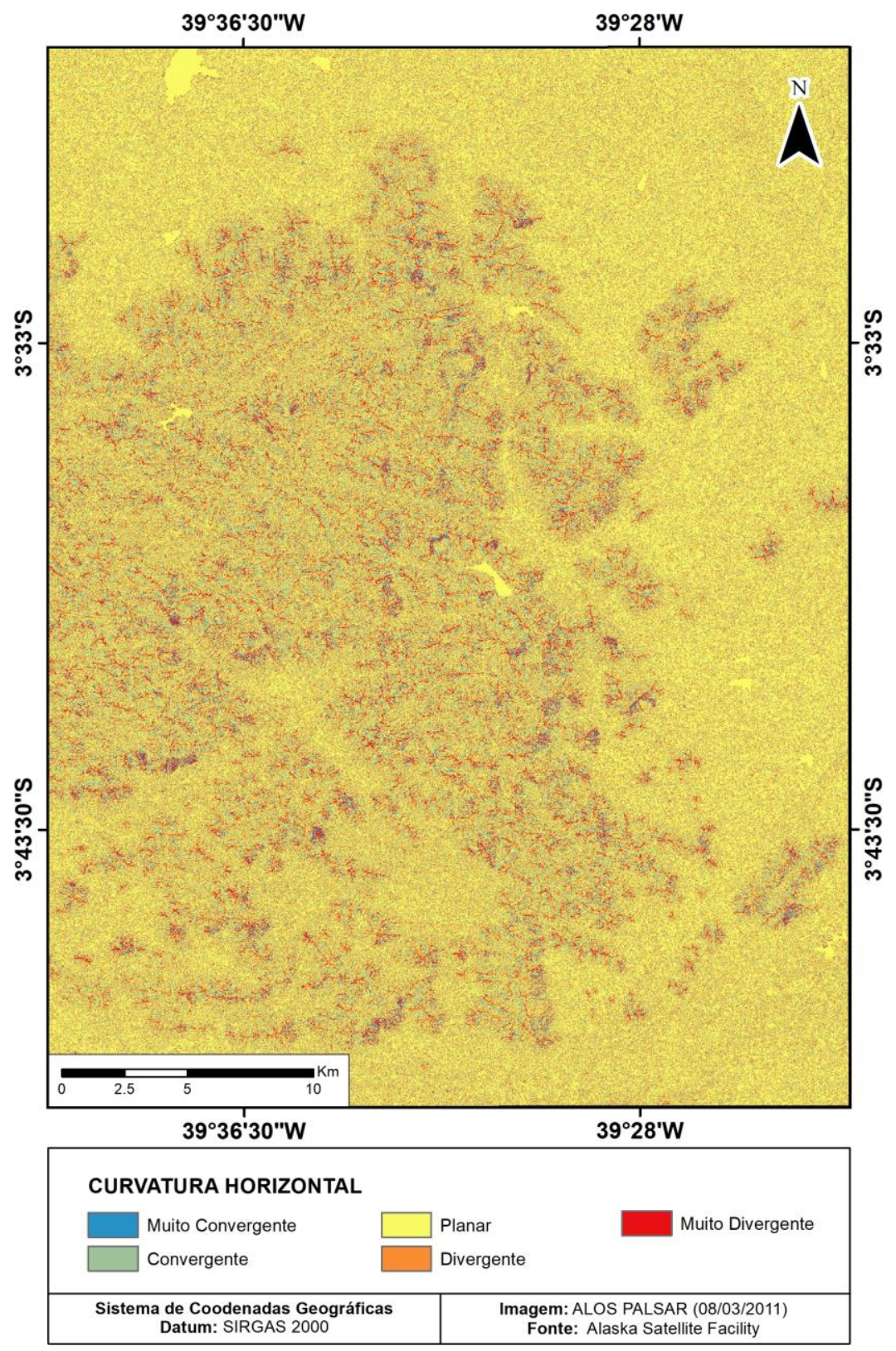

Figura 8 - Mapa de curvatura horizontal da vertente úmida da serra de Uruburetama.

\section{Orientação das vertentes}

A orientação de vertentes (ou direção) diz respeito ao ângulo azimutal correspondente à maior inclinação do terreno, no sentido descendente. É expressa em graus, de $0^{\circ}$ a $360^{\circ}$ e traduz a estrutura de hidrologia superficial, ao determinar um caminhamento esperado de escoamento que se costuma chamar de linhas de fluxo. As linhas de fluxo, os canais de drenagem e divisores de água podem ser definidos em função do arranjo local de diferentes orientações, o que fica prontamente visível em representações adequadas da variável (Valeriano, 2008).
Ao definir as linhas de fluxos é possível compreender a dinâmica e orientação do transporte sedimentar e dos movimentos gravitacionais. A esta variável, por apresentar menor contribuição na deflagração dos processos erosivos e movimento de massa, foi atribuído o menor peso percentual $(15 \%)$. Devido à disposição do relevo os setores a barlavento, com maior disponibilidade pluviométrica, receberam as maiores notas: nordeste (10), leste (9) e norte (8), enquanto que as menores notas foram atribuídas para noroeste (1), oeste (2) e sudeste (4). Na Figura 9 pode ser observado o mapa de orientação das vertentes da área de estudo. 


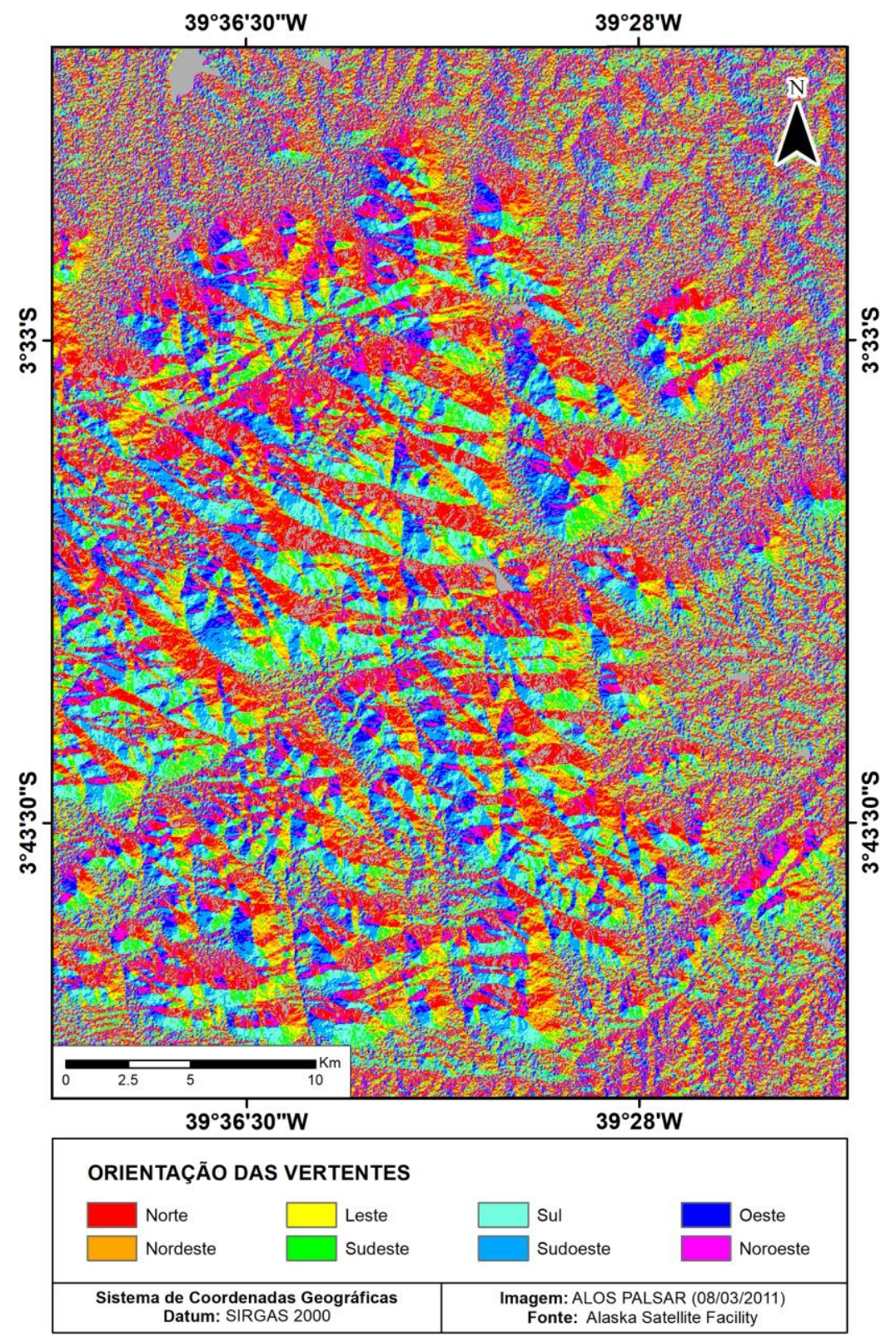

Figura 9 - Mapa de orientação das vertentes da vertente úmida da serra de Uruburetama.

Mapa de vulnerabilidade natural a perda de solos

O mapa de vulnerabilidade natural a perda de solos obtido através da análise multicritério e da álgebra dos mapas temáticos se encontra na Figura 10. Na Tabela 8 podem ser observadas as classes de vulnerabilidade com seus respectivos intervalos e áreas de abrangência.

Tabela 8 - Intervalos das classes de vulnerabilidade e abrangência em percentuais.

\begin{tabular}{ccc}
\hline Classes & Intervalos & \% \\
\hline Muito Baixa & $1-4$ & 38,92 \\
Baixa & $4-5$ & 29,71 \\
Média & $5-6$ & 23,40 \\
Alta & $6-7$ & 5,84 \\
Muito Alta & $7-10$ & 2,13 \\
\hline
\end{tabular}

As classes de vulnerabilidade muito baixa e baixa se distribuem principalmente na área de entorno da vertente úmida do maciço de Uruburetama. Essa área corresponde a depressão sertaneja, cujas cotas altimétricas atingem $200 \mathrm{~m}$ e as declividades são mais modestas. Em alguns setores do maciço podem ser observados vales encravados, marcados pela ocorrência de alveólos, formados ao longo do tempo por uma grande deposição de sedimentos que entulharam grandes seções, favorecendo a formação de solos e configurando ambientes estáveis, que apresentam vulnerabilidade baixa ou muito baixa conforme a topografia local.

Por sua vez as classes de vulnerabilidade média, alta e muito alta estão distribuidas principalmente nas encostas do maciço. As maiores altitudes verificadas nessas áreas, associadas ao percentual de declividade, formas das encontas e 
orientação das vertentes, favorecem a atuação dos agentes erosivos e desencadeadores de movimentos massa.

A ocorrência de classes vulnerabilidade alta e muito alta pode ser explicada pelo forte controle estrututral verificado no maciço. Por se configurar num relevo fortemente fraturado, com vales superimpostos em forma de $\mathrm{V}$, há um número expressivo de encostas submetidas a ação dos agentes intempéricos e consequentemente do transporte sedimentar, que favorece a esculturação do relevo e reflete a susceptibilidade desses ambientes aos processos morfogenéticos.

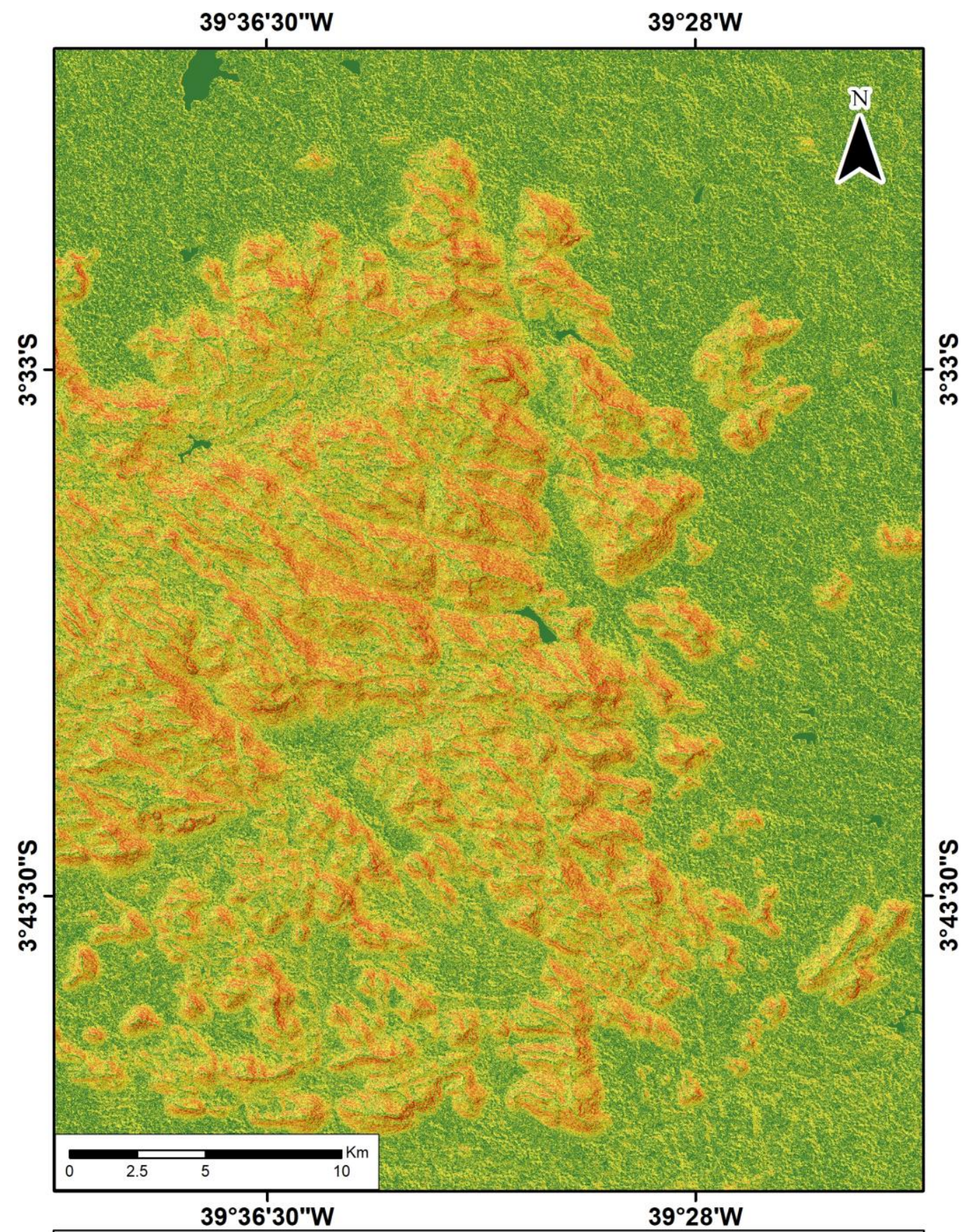

\begin{tabular}{|c|c|c|}
\hline \multicolumn{3}{|l|}{ Classes de Vulnerabilidade } \\
\hline Muito baixa & Média & Muito Alta \\
\hline Baixa & Alta & \\
\hline $\begin{array}{c}\text { Sistema de Coordenadas Geográficas } \\
\text { Datum: SIRGAS } 2000\end{array}$ & $\begin{array}{l}\text { Integra } \\
\text { vertical }\end{array}$ & $\begin{array}{l}\text { ividade, curvatura } \\
\text { áo das vertentes. }\end{array}$ \\
\hline
\end{tabular}

Figura 10 - Mapa de vulnerabilidade natural a perda de solos da vertente úmida da serra de Uruburetama 
É possível observar, também, que as classes de vulnerabilidade alta e muito alta estão dispostas sobretudo nas vertentes orientadas a leste, norte, e principalmente a nordeste do maciço. $\mathrm{O}$ fato da região leste do maciço apresentar um relevo escarpado e montanhoso, associado a sua disposição a barlavento, que favorece o efeito orográfico e maiores índices pluviométricos, tornam esse área mais vulnerável a degradação dos solos.

A partir do mapa de vulnerabilidade é possível orientar e fiscalizar o uso e a ocupação na vertente úmida do maciço de Uruburetama, visando reduzir os danos e garantir o desenvolvimento agrícola sustentável. Uma parcela significativa da população local vive da atividade agrícola familiar, nesse caso, é comum observar intervenções nas encostas que favorecem os processos erosivos. Como pode ser observado na Figura 11-A, muitos cultivos são praticados sem adoção de técnicas agrícolas adequadas. Neste caso, observa-se o condenável plantio morro abaixo, cujas culturas estão dispostas na direção do fluxo, favorecendo a erosão laminar e a perda gradual da produtividade do solo a partir da redução dos nutrientes.
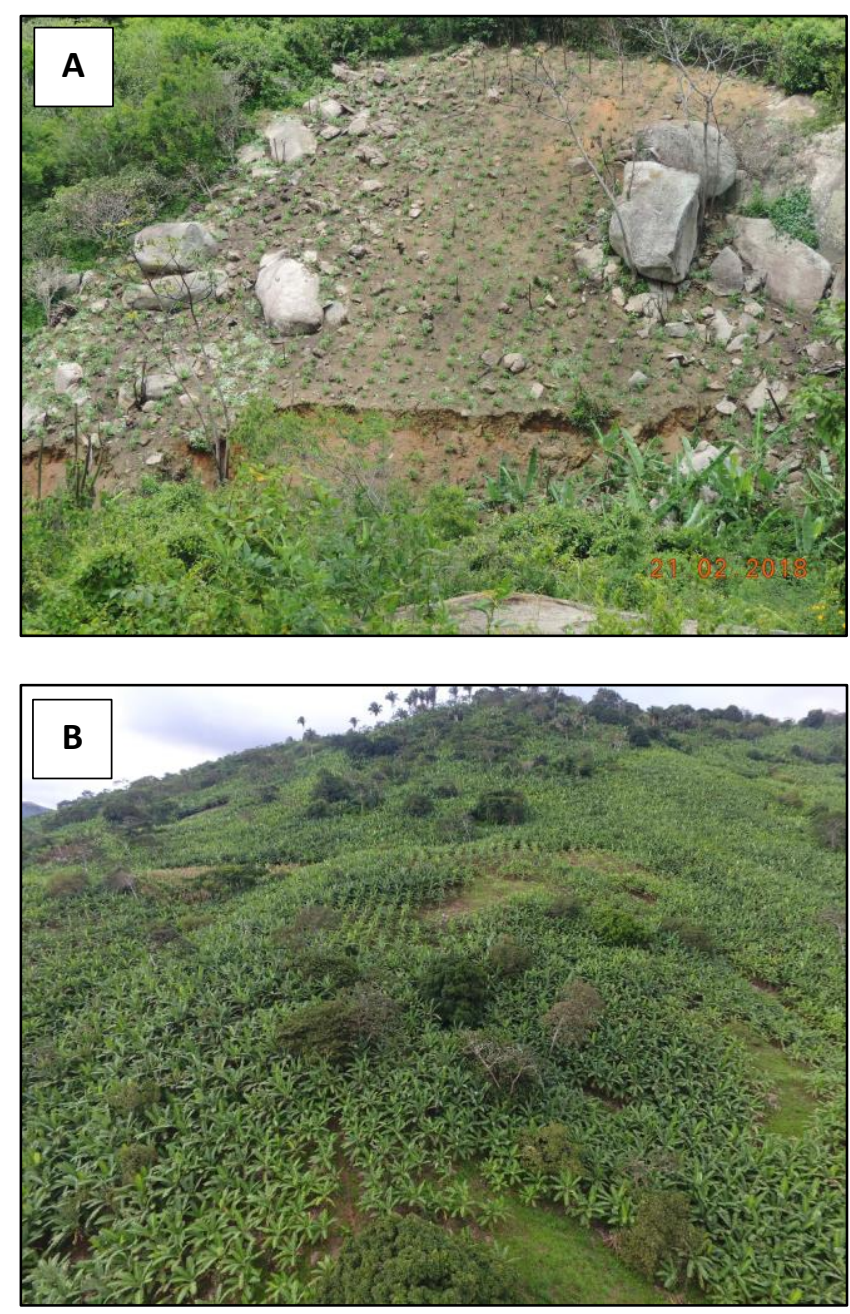

Figura 11- (A) Cultivos morro a baixo em Itapajé. (B) Bananicultura em Uruburetama.
Outro problema comum na área é o cultivo da banana (Figura 11-B), cultura completamente inadequada para áreas planálticas. Por apresentarem raízes rasas, as bananeiras não garantem a estabilidade dos solos e consequentemente potencializam os processos erosivos e o movimento de massa.

Além do mais, observa-se que nessas áreas são desenvolvidas atividades agrícolas em desacordo com o Código Florestal (Lei 12.651/2012), por serem praticadas em encostas com declividade superior a $45^{\circ}$ e em topo de morros acima de 100 metros de altitude.

Ao espacializar a vulnerabilidade natural a perda de solos dessas áreas é possível orientar as intervenções no sentido de compatibilizar as atividades aos limites impostos pelas características físicas do ambiente. Assim é possível identificar quais as áreas são mais adequadas à agricultura e a ocupação e o que pode ser feito para mitigar os impactos dessas ações, como o cultivo em patamares, através das curvas de nível, a adoção de culturas compatíveis as características de solo e clima local, a adequação do tipo de sistema de irrigação adotado e, bem como o atendimento às determinações do Código Florestal.

Conforme Ross (2004) é cada vez mais necessário que se faça inserções antrópicas absolutamente compatíveis com as potencialidades dos recursos naturais de um lado e com as fragilidades dos sistemas ambientais naturais de outro.

\section{Considerações finais}

Como pôde ser observado no mapa de vulnerabilidade natural à perda de solos, as classes de vulnerabilidade muito baixa e baixa se distribuem principalmente na área de entorno da vertente úmida do maciço de Uruburetama, que corresponde a depressão sertaneja, e em setores de alguns vales onde o processo de pedogênese é superior a morfogênese.

Por outro lado as classes de vulnerabilidade média, alta e muito alta estão distribuidas principalmente nas encostas do maciço em virtude das características de declividade, formas das encontas e orientação das vertentes. A interação desse fatores favorecem a atuação dos agentes erosivos e desencadeadores de movimentos de massa, que retratam o predomíno de processos modeladores do relevo, ou morfogênese.

Os resultados demostraram que as variáveis geomorfométricas, extraídas do MDE ALOS PALSAR, são bons recursos para análise de vulnerabilidade. 
O mapa de vulnerabilidade natural à perda de solos, obtido a partir das variáveis, geomorfométricas constitui um importante documento para gestão da área de pesquisa. A espacialização da vulnerabilidade permite ao gestor orientar as atividades econômicas e a ocupação humana respeitando os limites impostos pelos condicionantes físicos locais.

A partir da tomada de decisão pelos gestores ou órgãos competentes, as intervenções humanas no maciço podem ser pensadas no sentido de garantir maior produtividade e sustentabilidade a prática agrícola, seja pela adoção do cultivo em curvas de nível, para evitar a perda de solos, ou com a escolha de culturas adequadas às condições naturais do local, sempre respeitando a legislação ambiental vigente. Da mesma forma as ocupações das vertentes devem ser orientadas no sentido de evitar os riscos e as perdas ambientais e humanas.

\section{Agradecimentos}

Os autores agradecem a Fundação Cearense de Apoio ao Desenvolvimento Científico e Tecnológico (FUNCAP) e a Coordenação de Aperfeiçoamento de Pessoal de Nível Superior (CAPES) pelo auxílio financeiro concedido; e ao Programa de Pós-graduação em Geologia da UFC pelo incentivo a esta pesquisa.

\section{Referências}

Becek, K., 2014. Assessing global digital elevation models using the runway method: the advanced spaceborne thermal emission and reflection radiometer versus the shuttle radar topography mission case. IEEE Transactions on Geoscience and Remote Sensing 52, 4823-4831.

Bispo, P.C., Almeida, C.M, Valeriano, M.M, Medeiros, J.S, Crepani, E., 2011. Análise da suscetibilidade aos movimentos de massa em São Sebastião (SP) com o uso de métodos de inferência espacial. Revista Geociências 30, 467478.

Brandão, R.L., 2003. Zoneamento geoambiental da região de Irauçuba/CE. Texto explicativo. Carta Geoambiental. CPRM, Fortaleza.

Brandão, R.L., Freitas, L.C.B., 2014. Geodiversidade do Estado do Ceará. CPRM, Fortaleza.

Carmo, A.M., Souto, M.V.S., Duarte, C.R., 2015. Análise qualitativa e comparativa das variáveis morfométricas da região serrana da porção sul do maciço central do Ceará geradas através dos MDE: SRTM, ASTER GDEM E TOPODATA. Revista Brasileira de Cartografia 67, 603-620.

Coelho Netto, A.L., 2005. Hidrologia de encosta na interface com a geomorfologia, in: Guerra, A.J.T., Cunha, S.B. Geomorfologia - uma atualização de bases e conceitos. 6. ed. Bertrand Brasil, Rio de Janeiro, pp. 149-209.

Crepani, E., Medeiros, J.S.de, Azevedo, L.G.de, Hernandez Filho, P., Florenzano, T.G., Duarte, V., 1996. Curso de sensoriamento remoto aplicado ao zoneamento ecológico-econômico. Metodologia desenvolvida para subsidiar o Zoneamento Ecológico-Econômico e capacitar os técnicos dos Estados da Amazônia Legal. INPE, São Jose dos Campos.

Duarte, M.L., Silva, D.M.P., Silva, T.A., Guimarães, L.R., 2019. Evaluation of digital elevation models in the delimitation of hydrographic basins in the south of Amazonas region. Journal of Hyperspectral Remote Sensing 9, 99-107.

Dylik, J., 1968. Notion du versant em geomorphologie. Bulletin de l'Académie Polonaise des Scienses 16, 125-132.

EMBRAPA. Empresa Brasileira de Pesquisa Agropecuária, 2009. Sistema Brasileiro de Classificação de Solos. EMBRAPA-SPI, Rio de Janeiro.

Guerra, A.J.T., 2005. Processos erosivos nas encostas, in: Guerra, A.J.T., Cunha, S.B. Geomorfologia - uma atualização de bases e conceitos. 6. ed. Bertrand Brasil, Rio de Janeiro, pp. 149-209.

Hilberts, A.G.J., Loona, E.E.V., Trocha, P.A., Paniconi, C., 2004. The hillslope-storage Boussinesq model for non-constant bedrock slope. Journal of Hydrology 291, 160-173.

Jorge, M.C.O, Guerra, A.J.T., 2013. Erosão dos solos e movimentos de massa: recuperação de áreas degradadas com técnicas de bioengenharia e prevenção de acidentes, in: Guerra, A.J.T., Jorge, M.C.O. Processos Erosivos e Recuperação de Áreas Degradadas. Oficina de Textos, São Paulo, pp.7-30.

Loureiro, H. A. S., Ferreira, S. M., 2013. O papel das geotecnologias no estudo de feições erosivas e de movimentos de massa no Brasil. In: Guerra, A. J. T, Jorge, M. C. O. Processos erosivos e recuperação de áreas degradadas. Oficina de Textos, São Paulo, pp. 95-125.

Pradhan, B., 2010. Remote sensing and GIS-based landslide hazard analysis and cross-validation using multivariate logistic regression model on three test areas in Malaysia. Advances in Space Research 45, 1244-1256.

Ross, J.L.S., 2004. Geomorfologia aplicada aos EIAs-RIMA, in: Guerra, A.J.T., Cunha, S.B. Geomorfologia e Meio Ambiente. 5. ed. Bertrand Brasil, Rio de Janeiro, pp. 291-335.

Silva Neto, J.C.A., 2013. Avaliação da vulnerabilidade à perda de solos na bacia do rio Salobra, MS, com base nas formas do terreno. Revista Geografia 22, 5-25. 
Souza, M.J.N, Oliveira, V.P.V., 2006. Os enclaves úmidos e sub-úmidos do semi-árido do Nordeste Brasileiro. Mercator 5, 85-102.

Torres, F.T.P., Marques Neto, R., Menezes, S.O., 2012. Introdução à Geomorfologia. Cengage
Learning, São Paulo.

Tricart, J., 1977. Ecodinâmica. IBGE, Rio de Janeiro. Valeriano, M.M., 2008. Topodata: guia para utilização de dados geomorfológicos locais. INPE, São José dos Campos. 